ISSN: 1838-2959

Volume 2, Issue 1, pp. 56-62

February 2011

\title{
Preparing people to make a difference: Transferable lessons from a first-year student leadership development program in New Zealand. A Practice Report
}

\author{
Hesham Elnagar, Lane Graves Perry and Billy 0'Steen \\ University of Canterbury
}

\begin{abstract}
The transition from a secondary to a university education environment is one rife with opportunity and novelty. It can be a difficult time for students as they begin to participate and take part in a new culture. Lessons learned from a specific program for first-year students, the Emerging Leaders Development Program (ELDP), provide an example of an initiative that not only assists with the transition, but also offers leadership development opportunities. Data collected from ELDP participants suggests that there are valuable, relatable, and transferable ideas that can inform the design and implementation of other transition programs generally, and leadership development programs specifically.
\end{abstract}

Please cite this practice report as:

Elnagar, H., Graves Perry, L. \& O’Steen, B. (2011). Transferable lessons from a first-year student leadership development program in New Zealand. A Practice Report. The International Journal of the First Year in Higher Education, 2(1). 56-62. doi: 10.5204/intjfyhe.v2i1.49

This practice report has been accepted for publication in Int J FYHE. Please see the Editorial Policies under the 'About' section of the Journal website for further information.

(C) Copyright of practice reports is retained by authors. As an open access journal, articles are free to use, with proper attribution, in educational and other non-commercial settings. ISSN: 1838-2959 


\section{Setting the Stage}

The University of Canterbury (UC) is located in Christchurch, New Zealand with a total student population of around 17,000 and offers 14 undergraduate degree qualification programs across five colleges and one School of Law. The vision statement of the UC is People prepared to make a difference.

This vision statement, originally developed in 2003, was reviewed and endorsed in 2009 with a change in the university's Senior Management Team (SMT) and ultimately a new Vice-Chancellor. In continuing with the vision statement, the new leadership team sought to develop further existing programs into an interpretation of the statement along the lines of preparing students to make a difference locally and globally through strengthening the collaborative interactions between students, staff, and the community. One particular program that has evolved with this interpretation of the vision statement is the Emerging Leaders Development Program (ELDP).

In 2003, UC began awarding NZ\$5,000 undergraduate scholarships to promising, entering first-year students from all over New Zealand. The scholarships were named the Emerging Leaders Scholarship and were awarded to students who showed both academic and leadership potential. Approximately 25 students were selected each year to receive this scholarship but had no additional formalised leadership development opportunities. In 2009, the program was restructured to focus on developing these identified "emerging leaders" into "emerged leaders." Because the idea and award for student leadership development existed, the next step was to design and implement a more formalised program to prepare and support leaders. This new program focus, as well as increasing the number of scholarships to 100 , was presented to UC's leadership team who supported it as an initiative that could further put into action the aspirations of the university's vision.

\section{Literature underpinning the ELDP restructure}

The elements of student engagement, involvement, and retention merged with the desire to develop leaders and ultimately served as a foundation and departure point for the ELDP. In identifying how university affects students, Pascarella and Terenzini (2005) note that students improve their leadership skills during university. Furthermore, they state that it is the "campus environment and the kinds of experiences students have that are more powerful determinants of student leadership development" (p. 237). Similarly, Kuh, KinZie, Schuh and Whitt (2005) affirm that what students do during their time at university is more important to the students' success than who they are or where they go to university. While what the students do during their time at university is important, what opportunities the university makes or designs are just as important and influential. Moreover, Tinto's (1988) Student Departure Theory identifies the first six months and more specifically the first six weeks of a student's transition from secondary to tertiary education as being a pivotal period for their retention and "that effective retention and the involvement of individuals in the social and intellectual life of the college [university] are one and the same" (p. 453, italics added). Thus, integrating formalised opportunities into a program for first-year students appears to be a good combination for student engagement. 
In many cases, leadership skills are influenced by the day to day activities and conditions that add up to equal a university experience. Zimmerman-Oster and Burkhardt (1999) found that students can improve their leadership skills further from formalised, purposive initiatives and saw the following as the top four student leadership development initiatives offered at the higher education level:

- $\quad$ Leadership workshops;

- $\quad$ Mentoring programs;

- Guest speakers; and

- Service/Community volunteer placement (p. 57).

In conjunction with those initiatives, they also identified the top four student leadership development improvement areas as:

- $\quad$ Civic/social/political awareness;

- $\quad$ Commitment to service;

- Communication skills; and

- $\quad$ Social/personal responsibility (p. 58).

Research shows how concentrated leadership development opportunities can develop leaders, get students involved in doing something with their peers, and in the case of UC, prepare people to make a difference. In conclusion, a first-year leadership program designed to provide interactive and collaborative opportunities among students may help bridge the gap between secondary and university environments.

\section{The ELDP journey and its new initiatives}

The restructure of the ELDP began with a staff member who sought information to design a leadership program that could meet the university's vision. This staff member discussed the idea of a leadership program with various stakeholders and uncovered an unpublished paper (Layn, 2009) that looked into the needs and wants of the past Emerging Leaders Scholarship recipients. The study showed that previous scholarship recipients desired more opportunities to interact with their peers, staff, and the university campus as a way to make their experience more worthwhile.

With that information, the research on student leadership development programs, and SMT's approval to restructure the ELDP, the following initiatives were created and developed for ELDP participants to learn and apply concepts of leadership. Each initiative was supported by experiences and empirical evidence.

- $\quad$ ELDP Leadership Retreat (Eich, 2008; Zimmerman-Oster \& Burkhardt, 1999): A two day leadership retreat designed to introduce the ELDP participants to each other, the campus, and ideas on leadership. Active and collaborative learning opportunities in the form of experiential education were used (e.g. ropes course, Amazing UC Race, campus tour, and reflection on team dynamics). An academic component involved the participants learning from scholars in the field of leadership and about local not-forprofit community organisations.

- $\quad$ Group Service-Learning (Community Service) Projects (Dugan \& Komives, 2007; Eich, 2008; Zimmerman-Oster \& Burkhardt, 1999): Students worked in teams of 5-6 and identified areas of community concern to address. The student groups worked with local schools or not-for-profit community 
organisations in order to provide a needed service. This component of the ELDP took place over the duration of the academic year and involved a mid-year evaluation.

- $\quad$ Team Dinners (Dugan \& Komives, 2007; Eich, 2008): This was an opportunity for each team to meet with staff outside university operating hours to share a meal and have general conversations about the ELDP members' time at university. This was a great occasion to ask questions and continue to get to know each other. The team dinners were completed by the end of the first semester.

- $\quad$ Leadership Forums (Dugan \& Komives, 2007; Eich, 2008; Zimmerman-Oster \& Burkhardt, 1999): These development opportunities were designed to expose ELDP members to different paradigms, ideas, experiences, and perspectives on leadership. In the 2010 leadership forums, ELDP members heard from experts such as a renowned professional athlete, a grassroots community organiser who worked with the United Nations and a retired Royal Navy Commander. Also, they learned more about their strengths as a leader by participating in a forum facilitated by trained professionals in Strengths Finder 2.0 (Rath, 2007). From exposure to these various ideas of leadership, students were able to learn more about how leadership has been practiced and implemented into real life. Each forum included a 30 minute discussion.

- Closure (Reflection Session) (Eich, 2008): The reflection session was a way to end the year and provided the much needed opportunity for the ELDP participants to come together, discuss their experiences and perspectives on leadership and to illuminate lessons learned from the leadership forums and their community service projects. The reflection session helped identify what ideas the participants took away from their time in the ELDP.

Collectively, these initiatives represented the new opportunities offered to 2010 ELDP members. It was anticipated that implementation of these initiatives as formalised and co-curricular activities would create an environment conducive to student involvement and leadership development.

\section{Research: Implications for the ELDP and its members}

As more countries delve into researching student transitions, the question of research usefulness in informing program decisions remains important. As is sometimes an area of concern, research and reports can add fragments to a phenomenon in question rather than present a bigger picture for possible transfer (McInnis, 2001). The same is true regarding the implications for the ELDP. To understand what conclusions can be made from the restructure, students from the 2010 ELDP cohort were asked to participate in a study to gather their experiences from the program. Utilising questionnaires and interviews, the research aimed, as done with the 2009 cohort, to understand the students' perspectives. Different, however, was the orientation around the two more explicit foci of the program: leadership and service. By making the student voice the focus, the response again revealed a positive trend 
towards the shift to an FYE transition pedagogy.

Transition pedagogy, as used by Kift, Nelson and Clarke (2010), highlights what can be a progression for many institutions, including UC. The ELDP began in 2003 as a first generation extra-curricular program, which sought to identify potential leaders among entering first-year students but had not been developed to offer many other opportunities for students. With the new initiatives in place for 2010, the ELDP, according to transition pedagogy theory, had begun to evolve toward becoming a second generation co-curricular based FYE program.

Students responded positively to these new curricular program elements and initiatives (Elnagar, 2010). Particularly, there were detailed remarks regarding the leadership retreat and its affect on the students' confidence.

The initial leadership retreat was my first experience at the university and was very welcoming. Straight away it meant I knew people at the university.

For me, the most significant aspect was the retreat, as I met a lot of new friends who I have become close with, as well as having worthwhile personal experiences.

I found it great for getting out of my comfort zone and developing confidence to meet new people. It was good to have a new group of friends and a support base starting out on something new.

It was like I already had a place in the university before I started.

Confidence was described not only with the students' social interactions with one another, but also within their constructs of leadership and taking action. Involvement as a trend was also significant, as students responded positively to peer, staff, and university interaction which also focused to address student support and feedback.

I have found the guest speakers [forums] particularly helpful in my development as a leader. The ideas that these speakers have presented have underscored my previous understandings of leadership as well suggested new and fresh thoughts on leadership and service.

I believe helping in these service projects with my group pushed me out of my comfort zone, forced me to step up and do things to help others. This meant I had to have courage and be a positive role model for others.

The program coordinator was someone who was really speaking into what I'm sure a lot of us felt were really important issues, and just having someone that was so supportive, like someone who was actually excited to see what we could do.

At the time of the questionnaire, the students were looking forward to a final meeting/social gathering to exchange words, ideas, and stories as a way to reflect on the year. They also expressed a concern for future involvement and opportunity, mentioning how they would like to continue with the program, or be a part of it in some new way. Here the students are piecing together the next stage of FYE integration at the university and how various campus programs can begin to move towards a transition pedagogy. From this information, various campus departments have begun to connect opportunities for first-year students, particularly with mentoring (as both a mentee and potential mentor). Overall, the ELDP has undergone a major shift in its move from an extra-curricular to a 
co-curricular structure. As a result, the students' responses suggest that this has been a positive change particularly in terms of their confidence, extent of interaction with peers and familiarity with the campus and staff (Elnagar, 2010).

\section{Reflections, conclusions and takeaways}

New Zealand universities are beginning to shape their individual approaches to firstyear student needs, and as directed from the preliminary collections of student feedback in 2010, the ELDP has taken the needed steps towards developing a program and curriculum which serve the students' social, physical, emotional, and intellectual needs. With this program, the implications not only validate its recent restructure, but also present a transferable pattern understood in FYE development. The context which differentiates this program from others is its unique fusion of leadership and service-learning theories. By and large, from gathering students' perspectives, transition pedagogy has revealed itself as being the next necessary step towards preparing people to make a difference (Kift et al., 2010).

In reflection, this Practice Report was written to demonstrate how FYE programs can be developed with an emphasis that is greater than solely assisting with the secondary to university transition. In fact, the combination of the FYE with leadership development meets student expectations and enhances the effects on both. As demonstrated here, we believe leadership opportunities are influential catalysts for creating a positive environment for firstyear students. Examples of these lessons learned are demonstrated in the following three corollaries.
Corollary 1. From the social and academic side of integration, having a group of familiar people on a university campus can help students with their transition from secondary school to university life.

Corollary 2. Learning opportunities, in an extra- or co-curricular capacity with a team element, serve as sources for interaction among students, and this is a valuable method for fostering student growth, engagement, and integration.

Corollary 3. With regard to the previous corollaries, leadership skills can be developed and enhanced during undergraduate students' time at university, and a formalised, purposive emphasis on this development serves as a means to this end.

These corollaries were observed among the ELDP participants and are supported by findings in the research. By creating conditions for first-year students that generate interest, bring about collaboration, and utilise service, students may become more immersed more immediately with the university culture and subsequently become more engaged in that culture.

This report demonstrates the current efforts of first-year student research and planning at UC. Reflective of current situations for many universities around the world, this report shows the amount of time it takes to develop a program through gathering information, analysis, restructuring, and gathering more information. Although our context involves a combination of leadership and servicelearning opportunities, the key for us with the ELDP was to prioritize the student voice and concern. As McInnis (2001) mentioned, research on the first-year has not asked students enough questions 
regarding their transition process, but often rests on assumptions taken from reports which are not generaliseable beyond their specific contexts. Understanding the student perspective has provided invaluable insight on both the specifics of the program and its broader developments. Research on the ELDP has presented information for moving towards a transition pedagogy. In fact, the students themselves revealed the necessary next steps, which is consistent with trends at other institutions. By then addressing student needs, elements specific to each institutional context can aid the transition process with the goal of creating an environment that is committed and student-focused (Kift et al., 2010).

\section{References}

Dugan, J. P. \& Komives, S. R. (2007). Developing leadership capacity in college students: Findings from a national study. A Report from the MultiInstitutional Study of Leadership. College Park, MD: National Clearinghouse for Leadership Programs.

Eich, D. (2008, November). A grounded theory of highquality leadership programs: Perspectives from student leadership development programs in higher education. Online Journal of Leadership and Organizational Studies. Retrieved on September 28, 2010, from http://www.entrepreneur.com/tradejournals/ article/187962045.html

Elnagar, H. (2010). The perceptions of participants in a First-year Experience Program at a New Zealand university. Unpublished manuscript, University of Canterbury.

Kift, S. M., Nelson, K. J. \& Clarke, J. A. (2010). Transition pedagogy: A third generation approach to FYE-A case study of policy and practice for the higher education sector. The International Journal of the First Year in Higher Education, 1(1), 1-20. doi: 10.5204/intjfyhe.v1i1.13.

Kuh, G., Kinzie, J., Schuh, J. \& Whitt, E. (2005). Student success in college: Creating conditions that matter. San Francisco: Jossey-Bass.
Layn, Z. (2009, September). Emerging leadership scholarship: Insights from past members. A discussion paper. Unpublished manuscript, University of Canterbury.

McInnis, C. (2001). Researching the First Year Experience: Where to from here? Higher Education Research \& Development, 20(2), 105-114. doi: 10.1080/07294360125188.

Pascarella, E. T. \& Terenzini, P. T. (2005). How college affects students: Volume 2. A third decade of research. San Francisco: Jossey-Bass.

Rath, T. (2007). Strengths finder 2.0. New York: Gallup Press.

Tinto, V. (1988). Stages of student departure: Reflections on the longitudinal character of student leaving. The Journal of Higher Education, 59(4), 438-455.

Zimmerman-Oster, K. \& Burkhardt, J. C. (1999). Leadership in the making: Impact and insights from leadership development programs in U.S. colleges and universities. Battle Creek, MI: W. K. Kellogg Foundation. 